Academic Platform Journal of Engineering and Science

journal homepage: http://apjes.com/

\title{
Amorf Yarıiletken InTe İnce Filminin Üretilmesi ve Karakterizasyonu
}

\author{
${ }^{* 1}$ Handan Aydın, ${ }^{2}$ Fahrettin Yakuphanoğlu, ${ }^{3}$ Cihat Aydın \\ ${ }^{1}$ Munzur Üniversitesi, Mühendislik Fakültesi, Metalurji ve Malzeme Mühendisliği, Tunceli, Türkiye \\ haydin@munzur.edu.tr, \\ ${ }^{2}$ Fırat Üniversitesi, Fen Fakültesi, Fizik Bölümü, Elazığ, Türkiye \\ fyhan@hotmail.com, \\ ${ }^{3}$ Mersin Üniversitesi, Mühendislik Fakültesi, Metalurji ve Malzeme Mühendisliği, Mersin, Türkiye \\ cihataydin@mersin.edu.tr,
}

Araștırma Makalesi

Geliş Tarihi: 10.07.2018

Kabul Tarihi: 02.01.2019

$\ddot{O} z$

Bu çalışmada, InTe amorf yariiletken malzemenin, X ışını difraksiyonu, elektriksel iletkenliği, optik ve dielektrik özellikleri araştırıldı. X-1şını difraksiyon sonuçları InTe numunesinin amorf yapıya sahip olduğunu gösterir. Numunenin elektriksel iletkenliğinin sıcaklığa bağlılı̆̆ araştırıldı ve bulunan sonuçlar numunenin bir amorf yariiletken olduğunu doğrular. InTe numunesi fotoiletkenlik özellik gösterir. Numunenin optik band aralığı ve optik sabitleri geçirgenlik ve yansıma spektrumları kullanılarak hesaplandı. Numunede doğrudan optik geçişler meydana geldi. Numunenin kırılma indisi dispersiyon eğrisi tek osilatör modeline uydu. Numunenin dielektrik özellikleri frekansın ve sıcaklığın bir fonsiyonu olarak araştırıldı. Dielektrik parametrelerin sıcaklık ve frekansla değiştiği bulundu. Elektrik modulus eğrileri dielektrik relaksasyon olayını analiz etmek için kullanıldı.

Anahtar Kelimeler: InTe, Elektriksel İletkenlik, Amorf Yariletken, Dielektrik Sabiti.

\section{Fabrication and Characterization of Amorphous Semiconductor InTe Thin Film}

\author{
${ }^{* 1}$ Handan Aydın, ${ }^{2}$ Fahrettin Yakuphanoğlu, ${ }^{3}$ Cihat Aydın \\ ${ }^{1}$ Department of Metallurgy and Materials Engineering, Faculty of Engineering, Munzur University, Tunceli, Turkey \\ haydin@munzur.edu.tr \\ ${ }^{2}$ Department of Physics, Faculty of Science, Firat University, Elazig, Turkey \\ fyhan@hotmail.com \\ ${ }^{3}$ Department of Metallurgy and Materials Engineering, Faculty of Engineering, Mersin University, Mersin, Turkey \\ cihataydin@mersin.edu.tr
}

\begin{abstract}
In this study, X-ray diffraction, electrical conductivity, optical and dielectrical properties of the InTe amorphous semiconductor material have been investigated. X-ray diffraction results show that InTe sample has an amorphous structure. Temperature dependence of electrical conductivity of the sample has been investigated and the obtained results confirm that InTe is an amorphous semiconductor. The InTe sample shows photoconductivity behavior. The optical band gap and optical constants of the sample were calculated using transmittance and reflectance spectra. In the sample, the direct optical transitions take place The refractive index dispersion curve of the sample obeys the single oscillator model. The dielectrical properties of the sample have been investigated as a function of frequency and temperature. It was found that the dielectrical parameters were changed with temperature and frequency. The electrical modulus curves were used to analyze the dielectrical relaxation processes.
\end{abstract}

Keywords: InTe, Electrical Conductivity, Amorphous Semiconductour, Dielectric constant.

\section{GİRIŞ}

Son yıllarda, amorf yariiletkenler güneş pili, ince film transistör, elektrofotoğrafik yazıcı, fotodedektör, elektronik anahtar ve bellek birimi gibi pek çok alanda yaygın olarak kullanılmaktadırlar. Yapılan çalışmalar kristal yarıiletkenlerle, uygun koşullarda hazırlanan amorf yarıiletkenlerin elektrik ve optik özelliklerinin birbirine 
benzediğini göstermiştir. Amorf yariletken malzemeleri elde etmek, kristal yariiletken malzemeleri elde etmekten daha kolay ve maliyeti daha ucuz olduğu için bu konuda yapılan çalışmalar giderek artmaktadır [1]. Amorf yariiletken filmlerin mikroelektronik teknolojisinde uygulama alanları gün geçtikçe artmıştır [2]. Amorf filmler, genelde özdirençleri yüksek olan As, Se, Te, S, Si ve Ge gibi elementlerle hazırlanırlar [3-4].

Amorf yarıiletkenlerin elektrik ve optik özelliklerinin kristal yariiletkenlerin özelliklerine benzerlik gösterdiği ilk olarak amorf Selenyum ile kristal Selenyum karşılaştırılması ile ortaya çıkarılmıştır [5]. Amorf Selenyum, 20. yüzyılın ilk yarısında Selenyum doğrultucularının fabrikasyonunda teknolojik olarak öneminin artmasının yanı sıra ilk fotokopyalama yöntemi kalkojen camlarla gerçekleştirilmiştir ve "xerography" adı verilen bu tekniğin ilk uygulaması 1956 yılında fotoiletken malzeme olarak Selenyum kullanılarak gerçekleştirilmiştir. Bu malzemeler halen fotokopi makinelerinde yaygin olarak kullanılmaktadır. Bir süre sonra amorf kalkojen camların anahtarlama ve bellek özellikleri bu alanda çalışan Ovshinsky tarafından 1968 yılında tespit edilmiştir. Doğru akım (DC) ve alternatif akım (AC) iletkenlik ölçümleri, cam sistemlerinde kusur etkileri ve iletkenlik mekanizmasını anlayabilmek için yaygın olarak kullanılırlar. Çok iyi bilinen $\sigma_{A C(W)}=A W^{S}$ denklemi bu iletkenlik mekanizmasının türünü açıklamak için kullanılmaktadır. $A C$ iletim mekanizmasını tanımlamak için Kuantum Mekaniksel Tünelleme (QMT) modeli [6,7], Bariyer Sıçrama (CBH (Correlated Barrier Hopping)) modeli [8,9] ve Büyük Polaron Tünelleme (QLPT) modeli [10] gibi birçok model önerilmiştir.

Son zamanlarda amorf yapıda dielektrik davranış gösteren ferroelektrik malzemeler geliştirilmektedirler [11,12]. Çünkü bunların optoelektronik özellikleri İndiyum kalkojenlerinin araştırmalarında büyük önem kazandı [13]. $I n_{2} T e_{3}$ çok ilginç elektriksel ve optiksel özelliklere sahip bir $A_{2}^{l l l} X_{3}^{V I}$ bileşiği [14,15] ve çinko sülfür yapısına sahiptir $[16,17]$. Birçok araştırmacı ince filmlerinin elektriksel özelliklerini araştırmıştır [18]. AC iletkenlik ölçümleri kalkojen yariiletkenlerin dielektrik özelliklerini ve elektriksel iletkenlik mekanizmalarını açıklamak için yaygın olarak kullanmaktadırlar. Bu çalışmada, hazırlanan InTe ince filminin elektriksel iletkenlik, optik ve dielektrik özellikleri araştırılmıştır. Elektriksel iletkenlik ölçümlerinden numunenin elektronik parametreleri hesaplanarak, elektriksel iletkenlik mekanizması belirlenmiştir. Numunenin fotoiletkenlik özellikleri farklı aydınlanma şiddetleri altında belirlenmiştir. Optik geçirgenlik ve optik yansıma spektrumlarından numunenin optik band aralığı ve optik sabitleri hesaplanmıştır. Kırılma indisi dispersiyon özellikleri tek osilatör modeli ile açıklanmıştır [19]. Dielektrik ölçümlerde ise, InTe ince filminin dielektrik sabitleri ve dielektrik relaksasyonu mekanizması belirlenmiştir.

\section{MALZEME VE YÖNTEM}

\subsection{Numunenin Hazırlanması}

İndiyum ve Teleryum tozları eşit atomik ağırlıklarda (\%99 saflıkta) karıştırıldı ve daha sonra $10^{-5}$ Torr'luk bir vakumda bir quartz tüpe yerleştirildi ve tüpün ağzı kapatıldı. Kapatılan quartz tüp, bir firına yerleştirildi ve sıcaklık $1073 \mathrm{~K}$ olarak ayarland1. Numune 24 saat bu sicaklıkta bekletildi ve daha sonra bileşik yavaşça oda sıcaklığına kadar soğutuldu. InTe külçesi tüp içerisinden çıkartıldı. Daha sonra elde edilen InTe külçesinden bir parça alınarak termal buharlaştırma sistemine yerleştirildi ve $2 \times 10^{-5}$ Torr vakumda bir cam üzerine buharlaştırıldı. Filmin kalınlığı Multiple Beam Interference (MBI) tekniği kullanılarak ölçüldü ve hazırlanan filmin kalınlığ $270 \mathrm{~nm}$ olarak bulundu.

\section{BULGULAR}

\subsection{X-Işını Difraksiyon Ölçümleri}

İnce filmin X-ışını spektrumu, Rigaku Geigerflex spektrometresi kullanılarak alındı. InTe ince filminin X-ışını difraksiyon deseni şekil 1'de gösterilmiştir. Şekil 1' deki spektrum geniş bir yayvan pik vermektedir. $\mathrm{Bu}$ pik numunenin amorf yapıya sahip olduğunu gösterir.

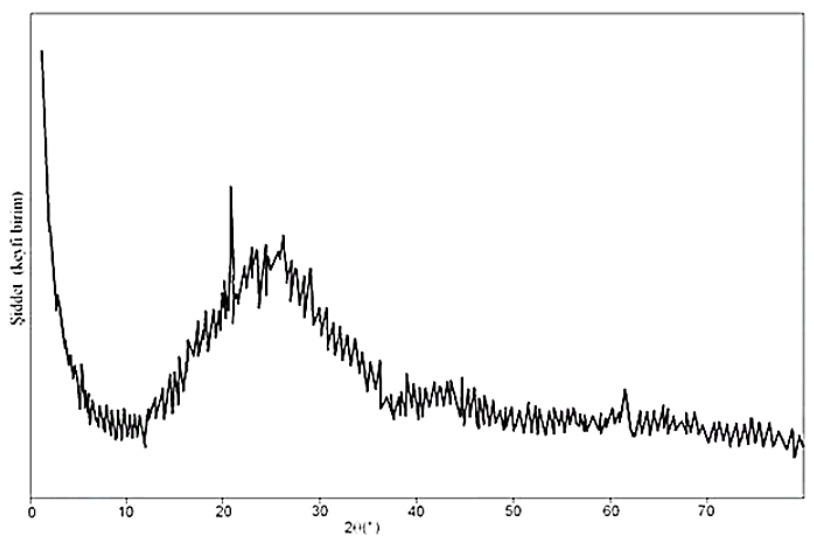

Şekil 1. InTe ince filmi X-1şını difraksiyon deseni.

\section{2. İletkenlik Sıcaklık Ölçümleri}

Yüksek dirençli malzemelerin elektriksel iletkenlik ölçümleri yapıldığında, ortamın akımları ölçümlerde hatalara neden olabilir. Ortam akımları statik veya piezoelektrik etkilerle malzemelerde yük depolanmasına neden olabilir. Ortam akımları uygulanan voltajla uyarılmış akımdan büyük veya eşit olmalıdır. Bu problem Değişken Polarite Metoduyla giderebilmektedir. Değişken Polarite Metodunda pozitif polariteli bir voltaj malzemeye uygulanır, daha sonra akım, belirlenmiş bir gecikmeden sonra ölçülür. Sonra voltajın polaritesi ters çevrilir ve akım aynı gecikme kullanılarak tekrar ölçülür. Bu işlem sonunda malzemenin iletkenliği belirlenir. İletkenlik ölçümleri değişken polarite metoduyla bilgisayar kontrollü olarak yapıldı. İletkenlik ölçümleri için şekil 2' de verilen deney düzeneği kullanılarak yapıldı. 


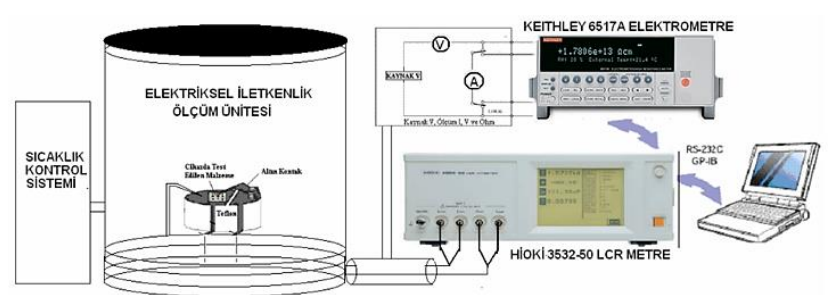

Şekil 2. Deney düzeneği

InTe ince filmin elektriksel iletkenliğinin sıcaklığa bağlılığ şekil 3' te verildi. Grafik yardımıyla ince filmin elektronik parametreleri ve iletkenlik mekanizması belirlendi. İletkenlik eğrileri Arrhenius eşitliği olarak bilinen:[31]

$\sigma_{D C}=\sigma_{1} \exp \left(-\frac{E_{a}}{k T}\right)$

denklem yardımıyla analiz edilmiştir. Denklem 1 'de verilen $\sigma_{1}$; üstel fonksiyon, $k$; Boltzman Sabiti ve $E_{a}$ ise Aktivasyon enerjisini temsil etmektedir. Elde edilen veriler 1şığında tüm numuneler için $\ln \sigma-1000 / T$ değişim grafikleri şekil 3' te gösterilmiştir. InTe numunesinin elektriksel iletkenliğin sıcaklığa bağlılığı grafiğinden görüldüğü gibi numunede tek bir iletkenlik mekanizması meydana gelmemekte ve numune farklı iki iletkenlik bölgesi (I. ve II.) göstermektedir. Numunenin iletkenlik mekanizması taşıyıcı yüklerin termal uyarılmasıyla meydana gelmektedir [20]. I ve II iletken bölgeler için aktivasyon enerjisi I. ve II. Bölgelerin eğiminden hesaplanarak tablo 1' de verildi. InTe filminin $27.6{ }^{\circ} \mathrm{C}$ sıcaklığındaki elektriksel iletkenliği $9.6 \times 10^{-8} \mathrm{~S} / \mathrm{cm}$ olarak bulundu. İletkenlik sonuçları InTe filminin yarıiletken yapıya sahip olduğunu göstermektedir.

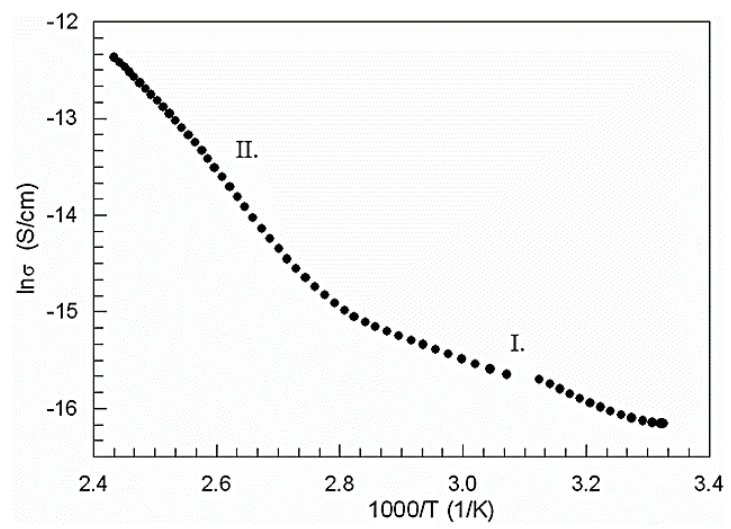

Şekil 3. InTe numunesinin $\ln \sigma-1000 /$ T grafiği.

\subsection{Optik Soğurma Ölçümleri}

InTe filminin yasak enerji aralığının belirlemek için bilgisayar kontrollü ve dalgaboyu 200-1100 nm aralığında olan UV-Vis Shimadzu 1240 spektrometresi kullanıldı. Numunenin optik soğurma spektrumu oda sicaklığında UVVis spektrometresi ile alındı. İnce filmin soğurma spektrumu oda sıcaklığında 200-1100 nm dalgaboyu aralığında alındı ve soğurma spektrumu şekil 4' te verildi. Elde edilen soğurma spektrumundan filmin yasak enerji aralığının hesaplanmasinda $[29,30]$ :

$\alpha h v=A\left(h v-E_{g}\right)^{m}$

formülü kullanılmıştır. Burada, $\alpha$; soğurma katsayısı, $h v$; foton enerjisi, $E_{g}$; Yasak Enerji Aralı̆̆ 1 ve $A$; sabittir. $m$ değeri 2 ise materyal dolaylı band aralığına, eğer $1 / 2$ ise materyal doğrudan band aralığına sahiptir. Elde edilen grafiklerde $m$ yerine $1 / 2$ konulduğunda en iyi lineerlik belirlenmiştir. Böylece yarıiletken ince film numunelerin doğrudan band geçişine sahip oldukları belirlenmiştir. Yapılan analizler sonucunda, numunenin band yap1s1 $(\alpha h v)^{2}$ $\mathrm{f}(\mathrm{E})$ ilişkisine uymaktadır (şekil 5). Bu grafiğin eğiminden yasak enerji aralığı hesaplanarak tablo 1' de verildi. InTe filminin doğrudan band yapısına sahip olduğu görüldü [21]. Yani $k=0$ durumunda valans bandinın maksimumu, iletim bandının minimuma karşılık gelmektedir [22-24]. Amorf malzemelerde düzensizlik ve uygulanan elektrik alan sonucunda filmlerin enerji bandlarında, bükülmeler yani band kuyruklanması oluşur. Band kuyruklanması özellikle amorf yariiletkenlerde meydana gelir ve bu da tuzak seviyelerinin genişliğine karşıllk gelir. Soğurma spektrumundan yararlanarak InTe filminin $\ln \alpha-\mathrm{f}(\mathrm{E})$ grafiğ $\mathrm{i}$ çizildi (şekil 6) ve çizilen grafiğin eğimlerinden, ince film için Urbach enerjisi hesaplandı ve tablo 1' de verildi. Optik soğurma ölçümleri genel olarak kimyacılar tarafından kimyasal bileşik içinde bulunan bileşenleri belirlemek için kullanılırken yarıiletken endüstrisinde, optik bant aralığ hakkında bilgi edinmek için kullanılır. Yalnız optik geçirgenlik ölçümlerinden (T) yararlanarak [25] veya optik yansıma ölçümlerinden $\mathrm{R}$ yararlanarak [26] yarıiletkenin optik soğurma katsayısının dalgaboyu (veya foton enerjisi) ile değişimi belirlenebilir. Numune için elde edilen geçirgenlik ve yansıma spektrumları sırasıyla şekil 8 ve 9'da verildi.

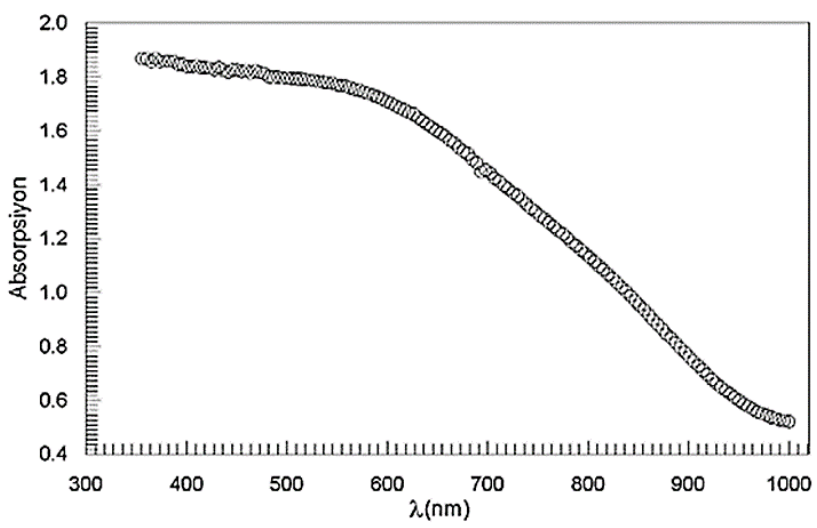

Şekil 4. InTe numunesinin optik soğurma spektrumu. 


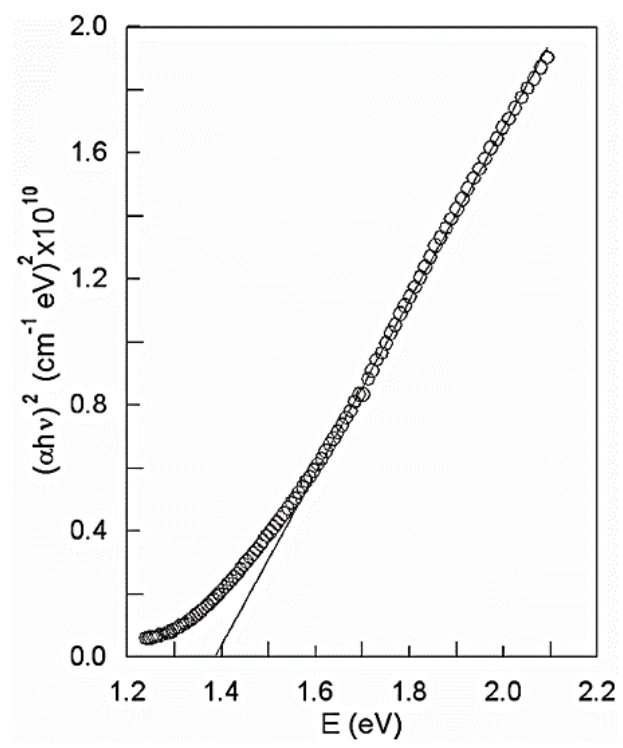

Şekil 5. InTe numunesinin $(\alpha h v)^{2}-E$ grafiği.

$\mathrm{Bu}$ spektrumlardan yararlanılarak numune için kırılma indisinin dalgaboyuna bağlılığı elde edildi ve şekil 9' da gösterildi. Kırılma indisi artan dalgaboyu ile azalmakta yani normal dispersiyon özelliği sergilemektedir. InTe filminin kırılma indisinin dispersiyon özelliğini analiz etmek için tek osilatör modeli kullanıldı. Dispersiyon teorisi, düşük emilim bölgesinde, kırılma indisinin ( $n$ ) etkili tek salınım modeline göre aşağıdaki denklem ile ifade edilmektedir: [32]

$n^{2}=1+\frac{E_{d} E_{o}}{E_{o}^{2}-(h v)^{2}}$

Bu denklemde $E_{o}$; salınım enerjisi, $E_{d}$; dispersiyon enerjisi ve $h v$; foton enerjisidir. Numunelere ait $E_{0}$ ve $E_{d}$ değerleri Şekil 10' da verilen $\left(\mathrm{n}^{2}-1\right)^{-1}$ 'ye karşı $E^{2}$ grafikleri yardımıyla hesaplanmış ve bu değerler Tablo 1' de verilmiştir. Bunun için InTe ince filminin $\left(n^{2}-1\right)^{-1}-(h v)^{2}$ grafiğ çizildi (şekil 10).

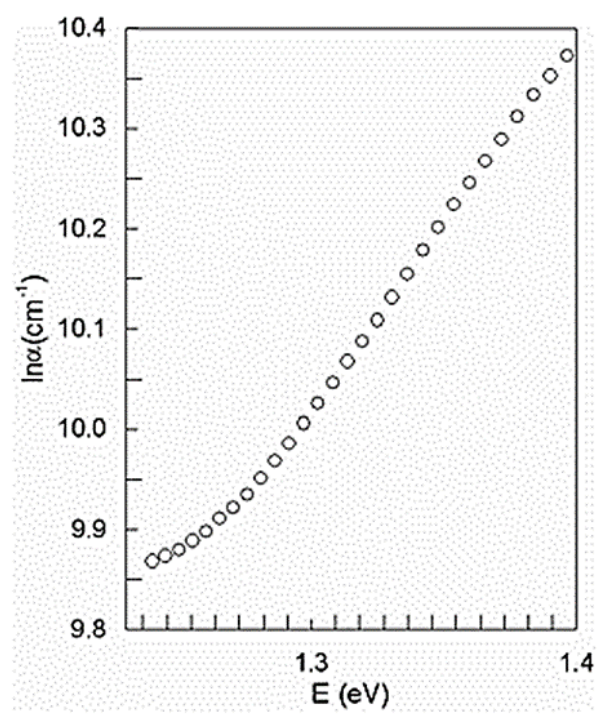

Şekil 6. InTe numunesinin $\ln \alpha-E$ grafiğgi.

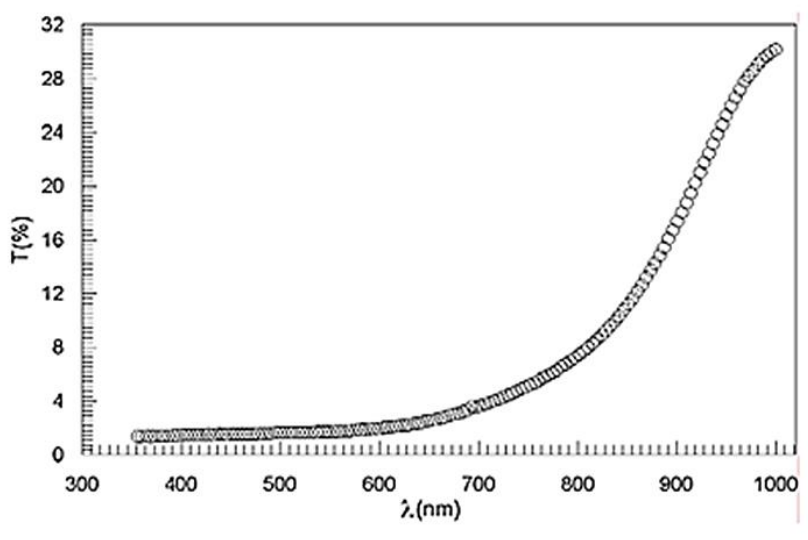

Şekil 7. InTe numunesinin optik geçirgenlik spektrumu.

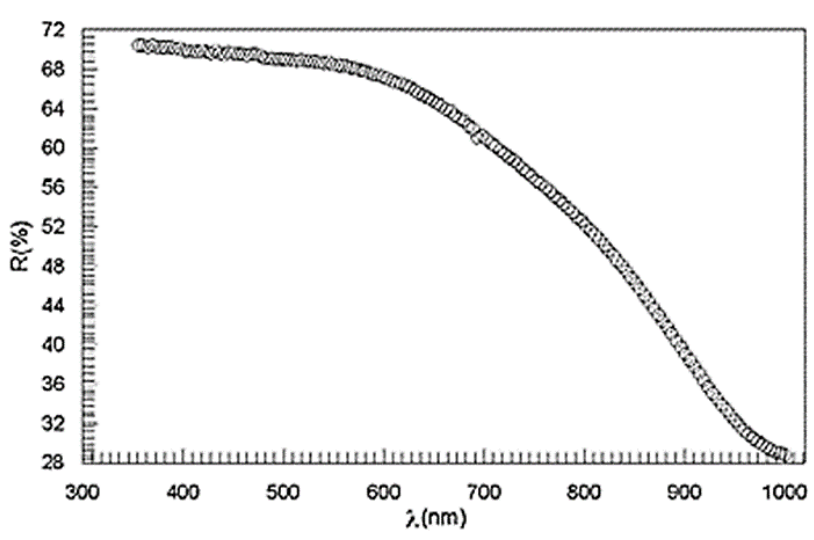

Şekil 8. InTe numunesinin optik yansıma spektrumu.

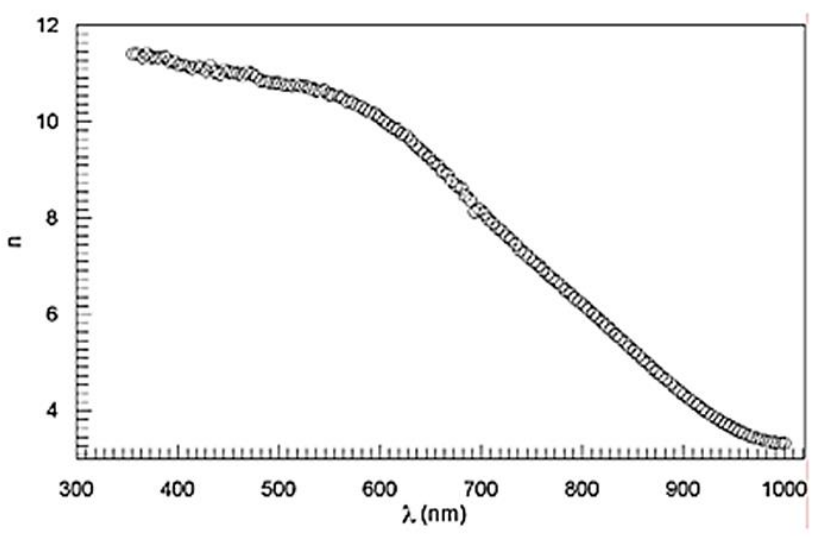

Şekil 9. InTe numunesi için kırılma indisinin dalgaboyuna bağlılı̆̆1.

Dielektrik sabiti, $\varepsilon=\varepsilon_{1}+i \varepsilon_{2}$ şeklinde yani, komplex dielektrik sabitinin gerçek ve sanal kısımları olarak tanımlanır. Bu durum aşağıdaki şekilde ifade edilir: [32]

$\varepsilon_{1}=n^{2}-k^{2}$

ve

$\varepsilon_{2}=2 n k$ 


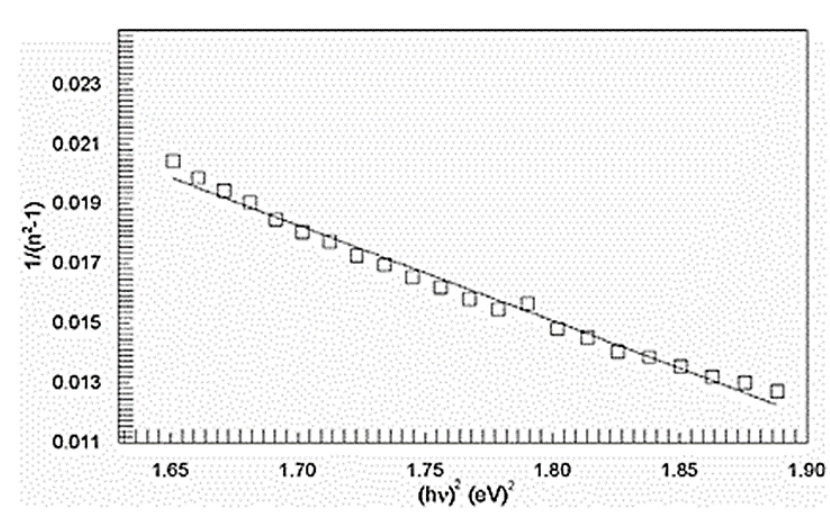

Şekil 10. InTe numunesinin $\left(\mathrm{n}^{2}-1\right)^{-1}-(h v)^{2}$ grafiğii.

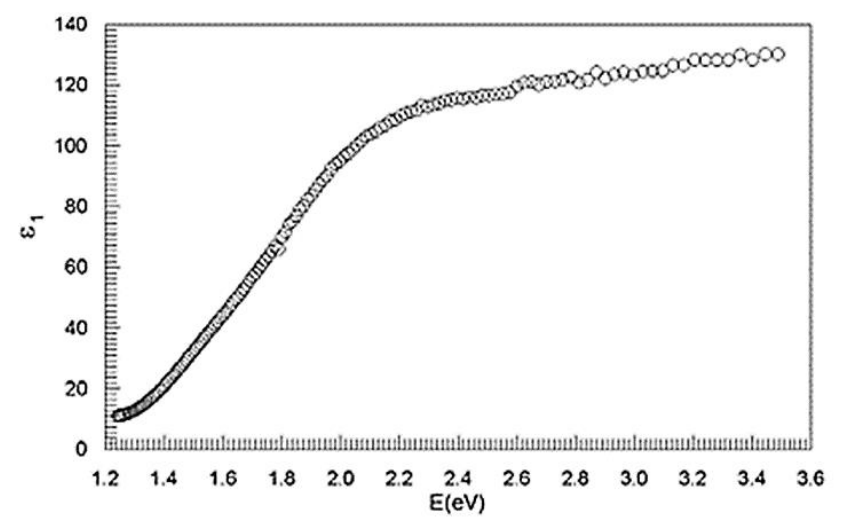

Şekil 11. InTe numunesinin $\varepsilon_{l}-E$ grafiği.

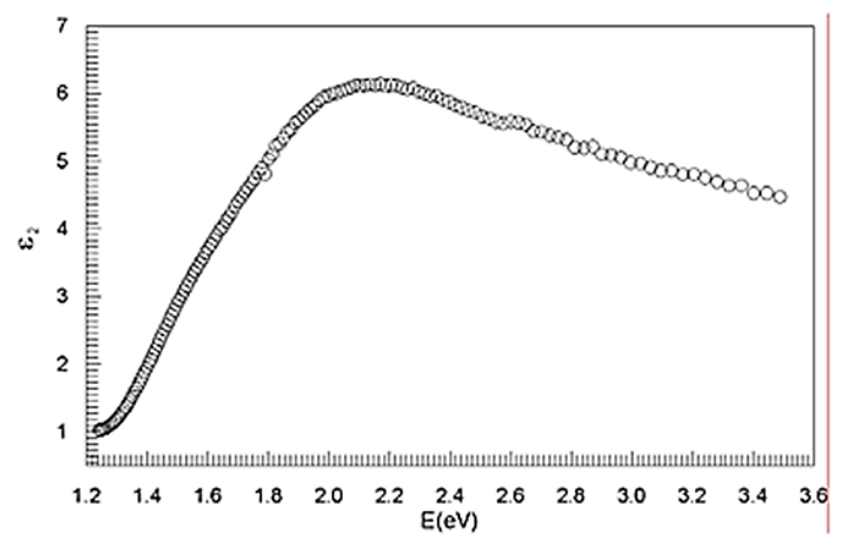

Şekil 12. InTe numunesinin $\varepsilon_{2}-E$ grafiği.

Dielektrik bağımlılığı Şekil 11 ve Şekil 12'de gösterilmektedir. InTe filminin optik dielektrik sabiti hesapland1. Kompleks dielektrik sabitinin gerçel $\left(\varepsilon_{l}\right)$ ve sanal kısımlarının $\left(\varepsilon_{2}\right)$ foton enerjisiyle $(h v)$ değişim grafikleri sırasıyla şekil 11 ve 12 'de verildi. Şekil 11'de görüldüğü gibi $\varepsilon_{1}$ foton enerjisiyle artmaktadır. Şekil 12' de ise dielektrik sabitinin sanal kısmı foton enerjisiyle artmakta ve belirli bir enerji değerinden sonra azalmaktadır. InTe numunesi için kompleks iletkenliğin reel ve sanal kısımlarının enerjiye bağlılığı sırasıyla şekil 13 ve 14' de gösterilmektedir. Optik iletkenlik enerjiyle artmaktadır [27].

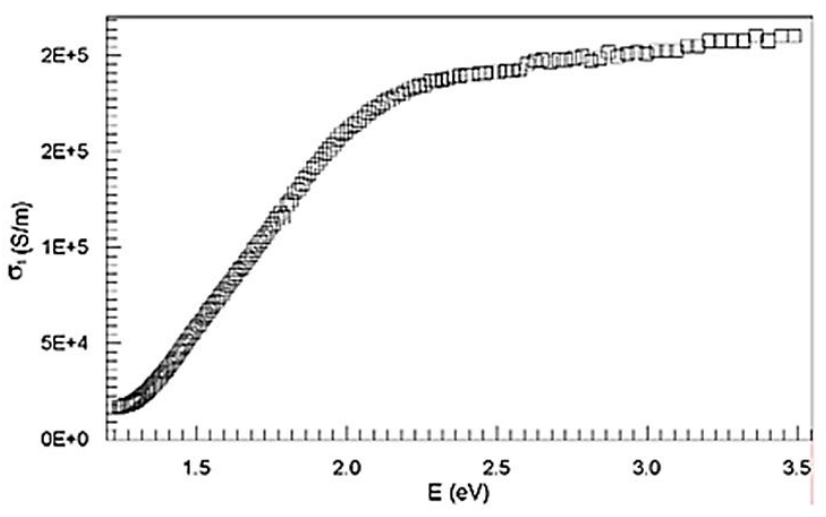

Şekil 13. InTe numunesinin $\sigma_{l}-E$ grafiği.

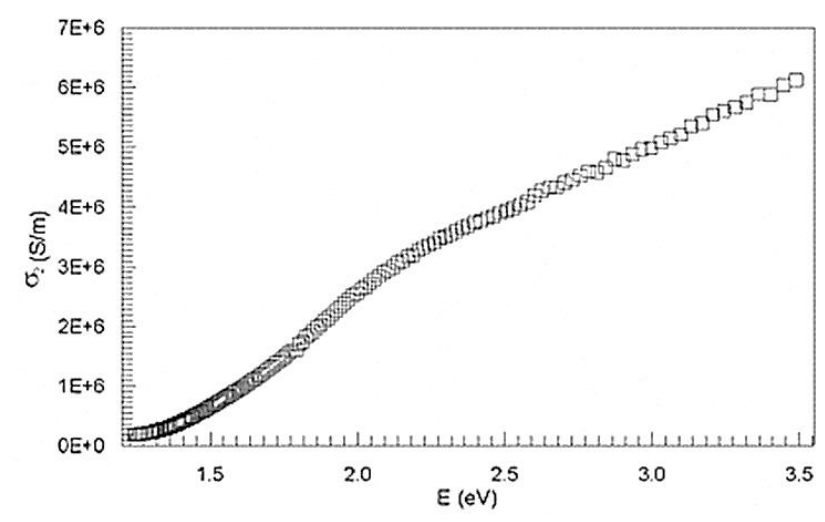

Şekil 14. InTe numunesinin $\sigma_{2}-E$ grafiğgi.

Tablo 1. InTe numunesinin optiksel parametreleri

\begin{tabular}{|c|c|}
\hline$E_{g}(\mathrm{eV})$ & 1.38 \\
\hline$E_{o}(\mathrm{eV})$ & 1.50 \\
\hline$E_{d}(\mathrm{eV})$ & 19.93 \\
\hline$E_{u}(\mathrm{eV})$ & 0.27 \\
\hline$\Delta E_{1}(\mathrm{eV})$ & 0.19 \\
\hline$\Delta E_{2}(\mathrm{eV})$ & 0.64 \\
\hline$n_{\infty}$ & 3.78 \\
\hline$\lambda_{0}(\mathrm{~nm})$ & 826.6 \\
\hline$S_{0}\left(\mathrm{~m}^{-2}\right)$ & $1.94 \times 10^{13}$ \\
\hline
\end{tabular}

\subsection{Fotoiletkenlik Ölçümleri}

Fotoiletkenlik ölçümleri 6517A KEITHLEY elektrometresi ile yapıldı. InTe filmi iletkenlik ölçüm düzeneğine yerleştirildi. Elektrometre ve dijital kart yardımıyla farklı aydınlanmalar altında 200 Watt'lık bir beyaz 1 şık kullanılarak akım-zaman ve akım-voltaj ölçümleri yapıldı. 
InTe ince filminin akım-zaman ve akım-voltaj grafikleri sırasıyla şekil 15 ve 16 'da gösterilmiştir. Karanlık ve farklı aydınlanmalar altında ölçümler yapıldı. Kısa süreli akım grafiklerinde akım artan aydınlanma şiddeti ile artmaktadır. Grafiklerde kısa süreli akımlardaki yükseliş bölgesi verilmektedir. Akımdaki artış numunenin yasak enerji aralığındaki tuzak seviyelerindeki değişimi göstermektedir.

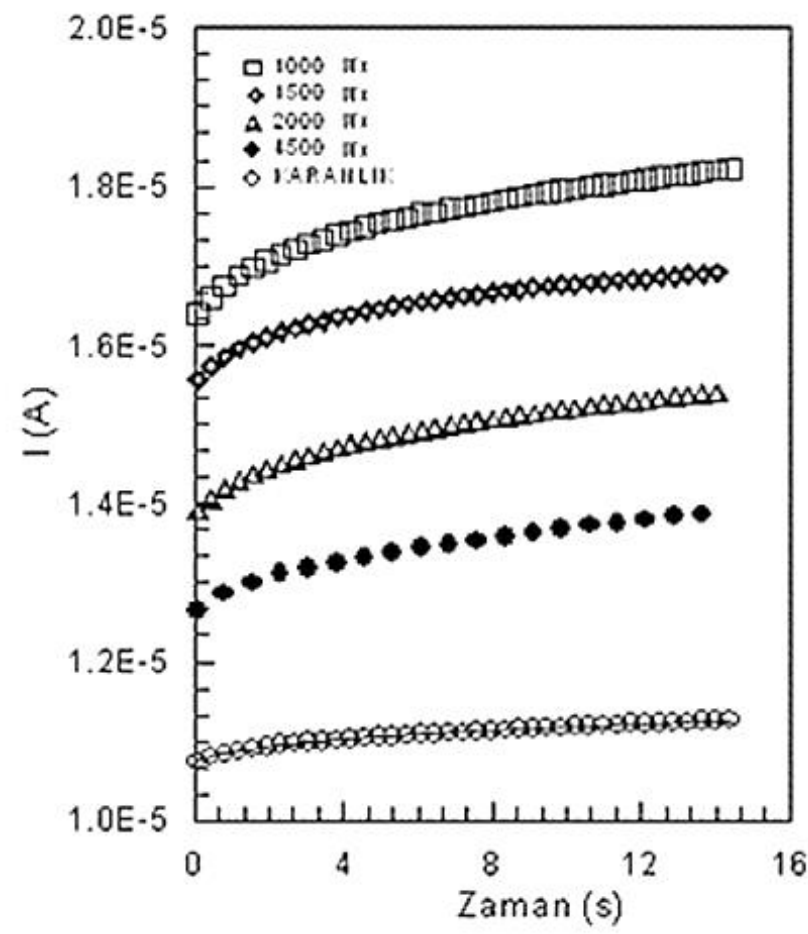

Şekil 15. InTe ince filminin farklı 1şı k şiddetlerinde akımın zaman ile değişimi.

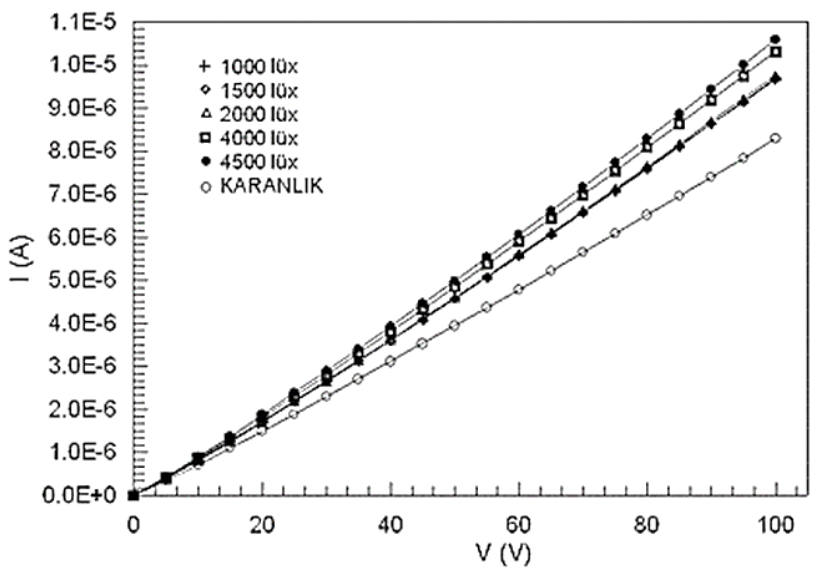

Şekil 16. InTe ince filminin farklı 1şık şiddetlerinde I-V grafiği.

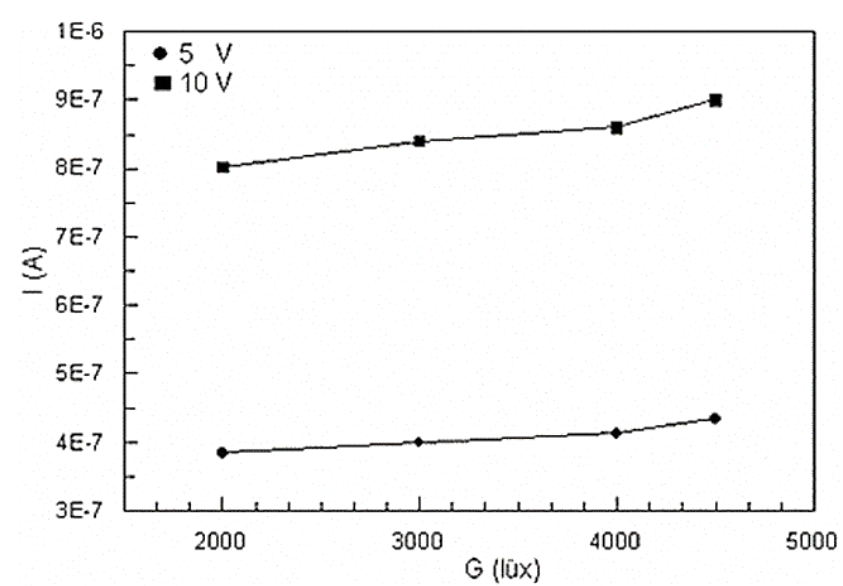

Şekil 17. InTe ince filminin I-G grafiği.

Akım-voltaj grafiklerinde ise, akım artan aydınlanma ile artmakta yani numune foto iletkenlik özelliği sergilemektedir (şekil 16). Akım-aydınlanma şiddetine bağlılı̆̆ı ise farklı voltaj için şekil 17'de verildi. Akım aydınlanma şiddetinin bir fonksiyonu olarak değişmektedir. Akımın aydınlanma şiddetiyle değişimi $I \infty G^{0.128}$ ve $I \infty G^{0.136}$ şeklinde bulundu.

\subsection{Dielektrik Ölçümleri}

Dielektrik ölçümleri HIOKI 3532-50 LCR cihazıyla farklı sicaklıklarda yapıldı. Otomatik olarak datalar bilgisayara aktarıldı. Elde edilen verilerle InTe filminin dielektrik özellikleri analiz edildi. InTe ince filminin alternatif akım (AC) iletkenliğinin frekansla ve sıcaklıkla değişimi şekil 18 ve 19'da gösterilmiştir. Şekil 18' den görüldüğü gibi düşük frekanslarda iletkenlik frekansla değişmemektedir. $\mathrm{Bu}$ değişim numune için doğru akım iletkenliğine karşı gelmektedir. Yüksek frekanslarda ise numunenin AC iletkenliği $\sigma \infty \omega^{S}$ bağıntısına uymaktadır. Şekil 19 'da görüldüğü gibi AC iletkenlik sıcaklıkla artmakta ve frekansla termal aktivasyon enerjisini değeri değişmektedir. Numunenin AC iletkenlik mekanizmasını belirlemek için şekil 18' deki eğrilerin eğiminden s değeri hesaplandi. s'nin sıcaklığa bağlılığı şekil 20' de verildi. s değerleri artan sicaklıkla azalmaktadır. Bu da numunede CBH (Correlated Barrier Hopping) iletkenlik mekanizmasının meydana geldiğini gösterir [28 ]. 


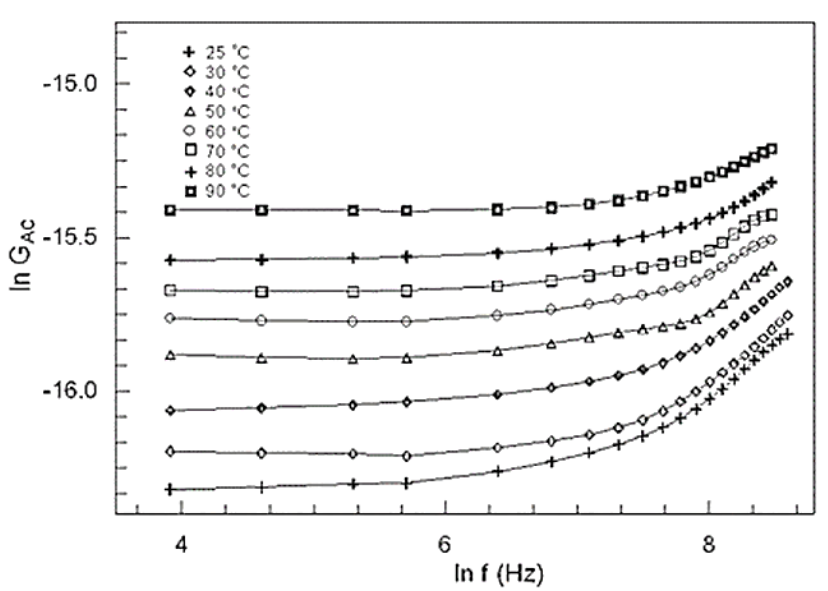

Şekil 18. InTe ince filminin farklı sıcaklıklarda AC iletkenlik grafiği.

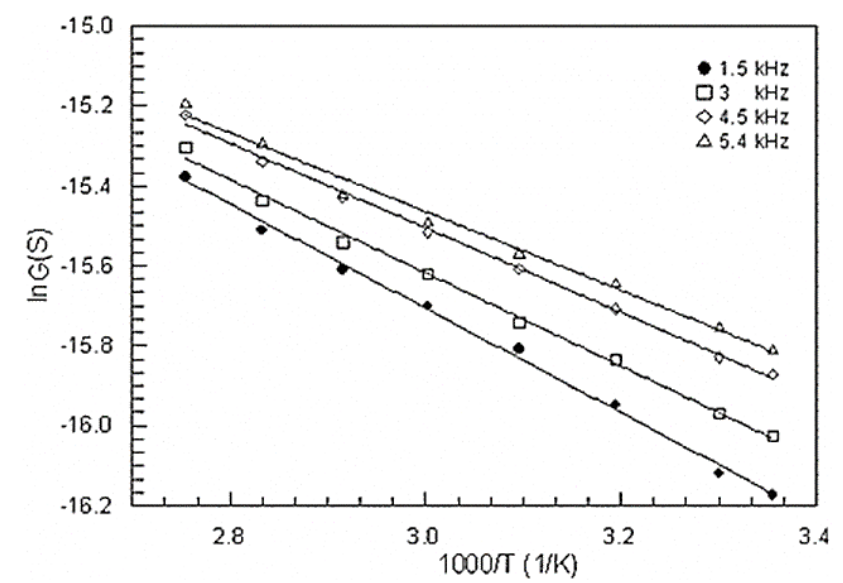

Şekil 19. InTe ince filminin AC iletkenlik grafiği.

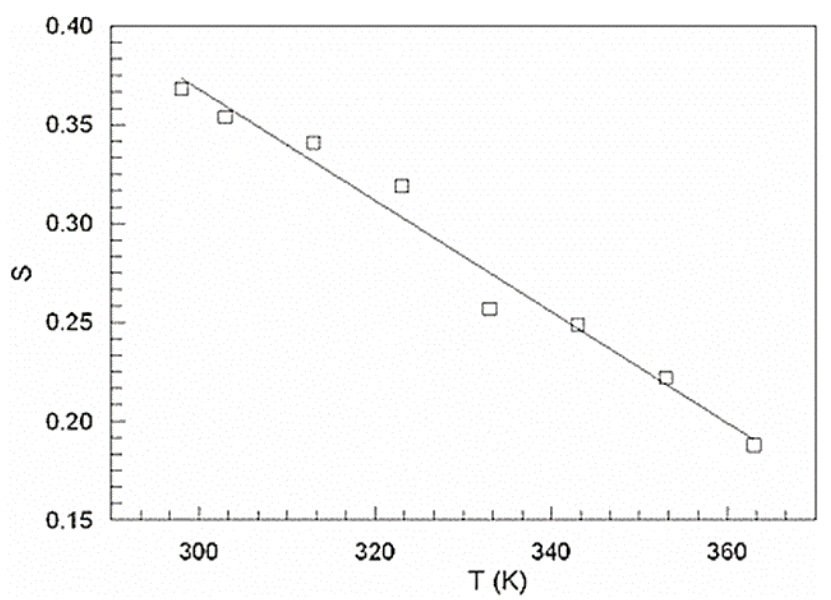

Şekil 20. InTe numunesi için farklı sıcaklıklarda s-T değişimi.
Dielektrik sabitinin reel ve sanal kısımları, farklı sıcaklıklarda frekansa bağlı olarak elde edilmiştir. Bunların frekansla ve sıcaklıkla değişimleri sırasıyla şekil 21 ve 22 'de gösterilmiştir. Numunenin dielektrik sabiti frekansla azalmakta ve sıcaklıkla ise artmaktadır. Dielektrik sabitinin reel kısmında benzer davranışı göstermektedir.

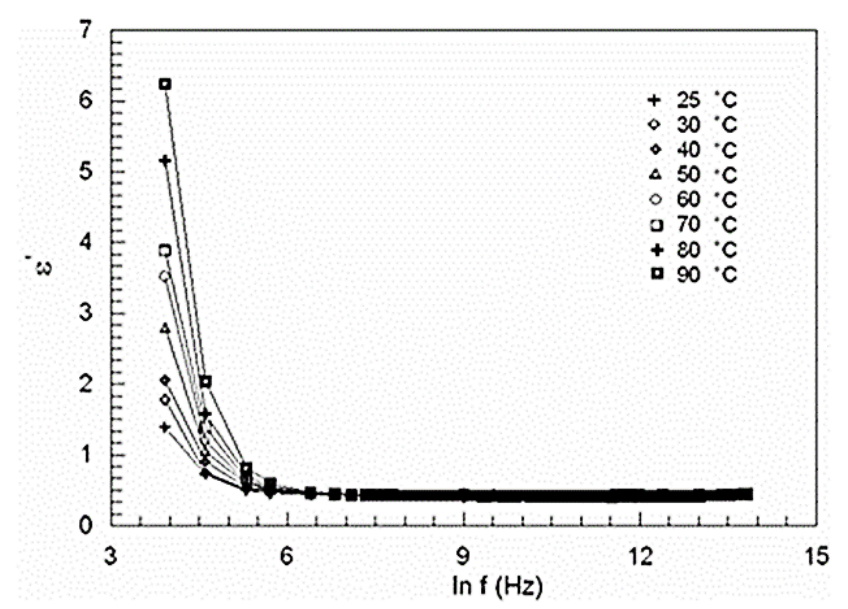

Şekil 21. InTe ince filminin farklı sıcaklıklarda $\varepsilon^{\prime}-\ln f$ grafiği.

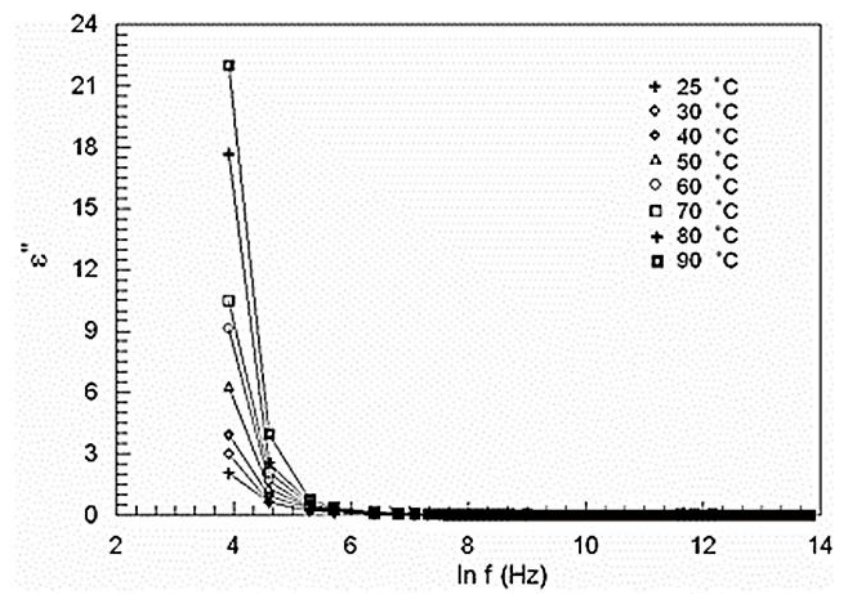

Şekil 22. InTe ince filminin farklı sıcaklıklarda $\varepsilon^{\prime \prime}-\ln f$ grafiği.

Elektrik modulusun gerçel ve sanal kısımları, farklı sıcaklıklarda frekansa bağlı olarak elde edildi. Bu parametrelerdeki değişimler sirasıyla şekil 23 ve 24'te gösterilmiştir. Şekil 23'ten görüldüğü gibi $\mathrm{M}^{\prime}$ frekansla artmakta ve yüksek frekans bölgesinde sabit bir değere ulaşmaktadır. 


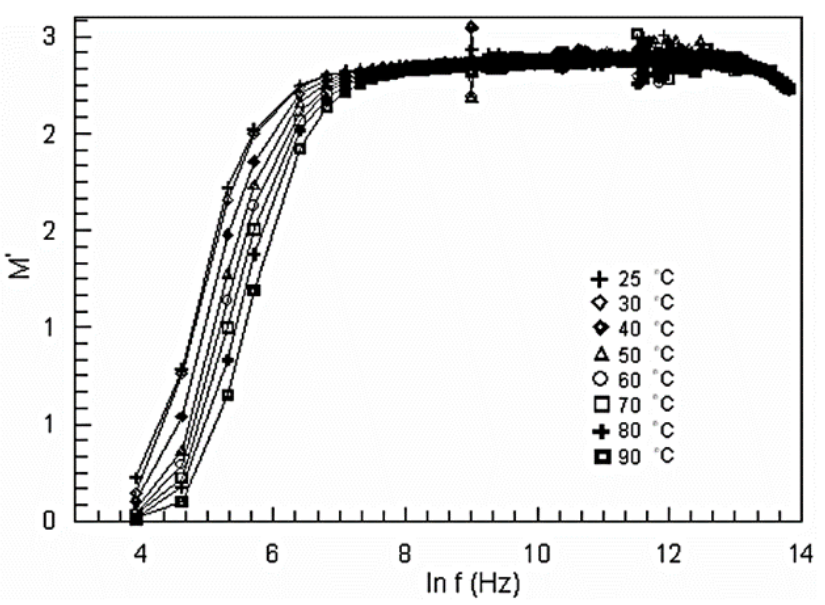

Şekil 23. InTe ince filminin farklı sıcaklıklarda $M^{\prime}-\ln f$ grafiği.

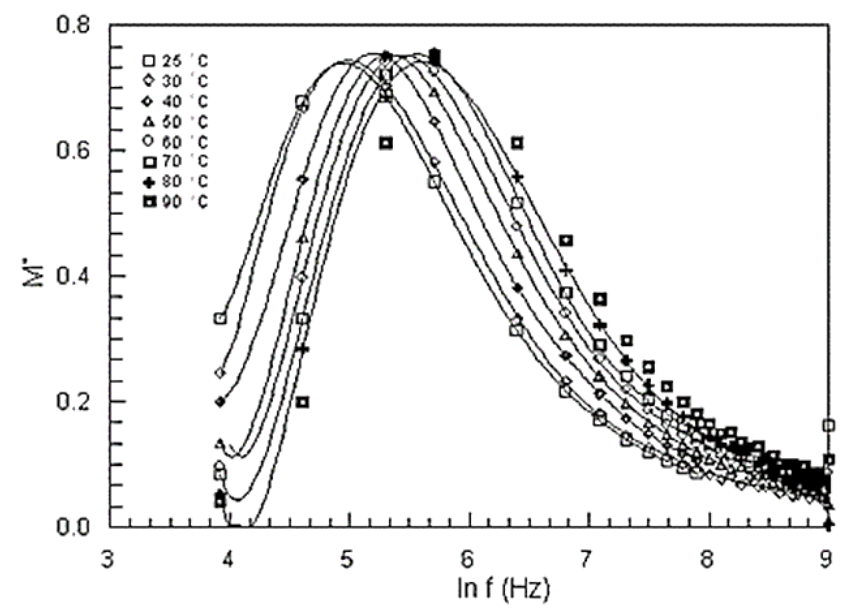

Şekil 24. InTe ince filminin farklı sıcaklıklarda $M^{\prime \prime}-\ln f$ grafiği.

Numunenin M"-lnf grafiği ise bir pik göstermekte ve bu pikin pozisyonu sıcaklıkla değişmektedir. $\mathrm{Bu}$ değişimde numunede sıcaklığa bağlı bir relaksasyon olayının meydana geldiğini göstermektedir. $\mathrm{Bu}$ piklerden yararlanarak, relaksasyon zamanı farklı sıcaklıklar için hesaplandı. Relaksasyon zamanının sıcaklığa bağlılığı şekil 25 'te verildi ve bu grafiğin eğiminden relaksasyon olayının aktivasyon enerjisi değeri hesaplandı ve $0.12 \mathrm{eV}$ olarak bulundu. Numunenin empedansının frekansa ve sıcaklığa bağlılığı araştırıldı ve elde edilen grafik şekil 26'da verildi. Şekilden görüldüğü gibi düşük frekans bölgesinde empedans sıcaklıkla azalmaktadır. Farklı sıcaklıklarda dielektrik kayıp faktörünün tan $\delta^{\prime}$ nın frekansla değişimi şekil 27' de gösterildi. Dielektrik kayıp değeri frekansla azalmakta olup,fakat sıcaklıkla artmaktadır.

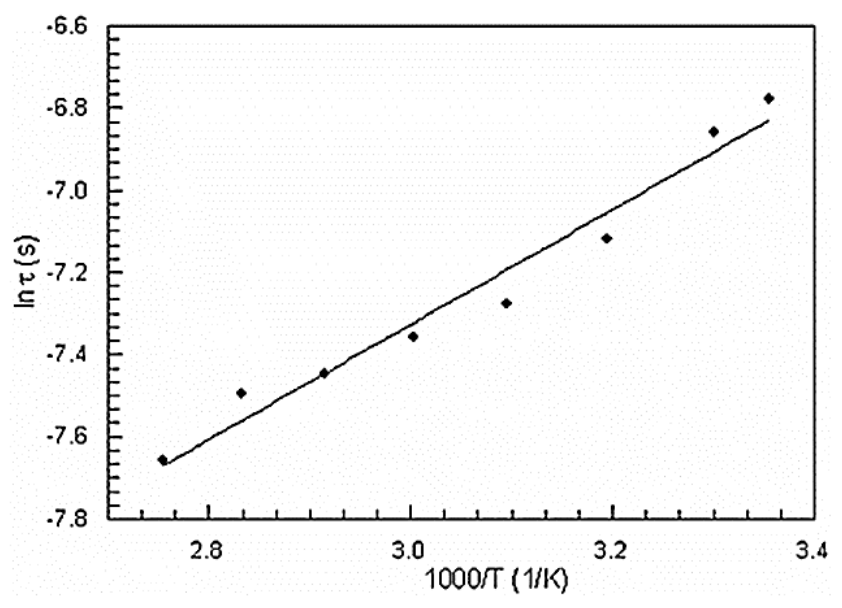

Şekil 25. InTe numunesinin $\ln \tau-1000 / T$ grafiği.

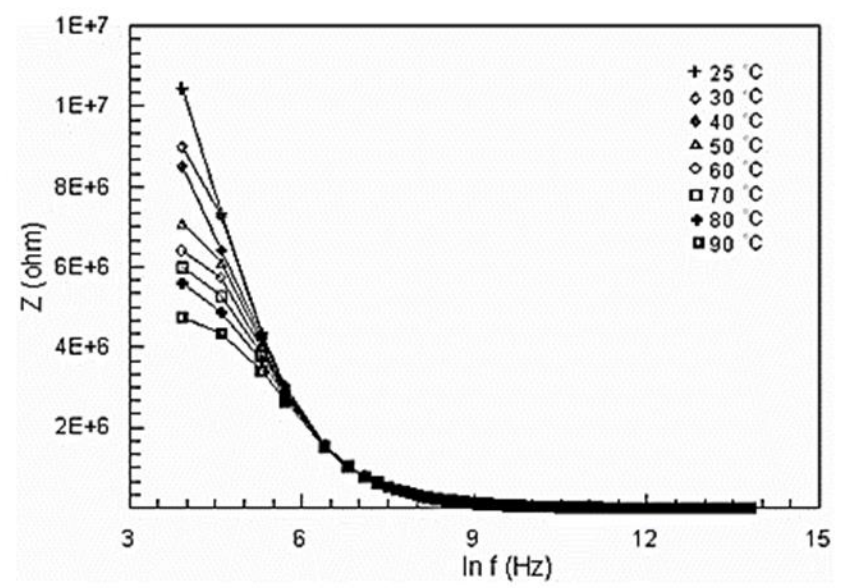

Şekil 26. InTe ince filminin farklı sıcaklıklarda $Z$ - $\ln f$ grafiği.

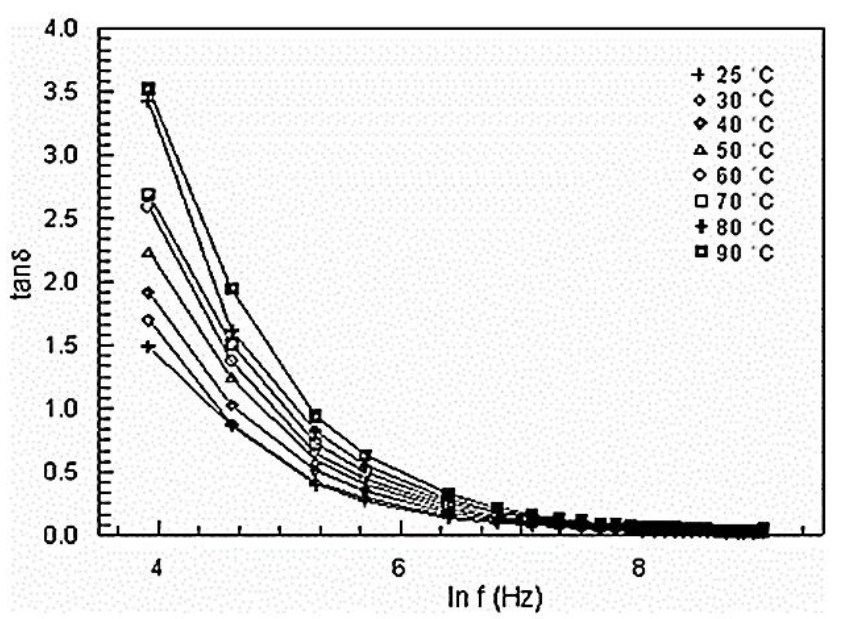

Şekil 27. InTe ince filminin $\tan \delta$-lnf grafiği. 


\section{DEĞERLENDİRME VE SONUÇ}

$\mathrm{Bu}$ çalışmada InTe ince filminin elektriksel iletkenlik, fotoiletkenlik, optik ve dielektrik özellikleri araştırıldı. Numunenin kristal yapısı X-1şını difraksiyonu ölçümüyle belirlendi ve X- 1şını ölçümlerinden numunenin amorf yapıya sahip olduğu görüldü. Numunenin elektriksel iletkenliği sıcaklığa bağlı olarak araştırıldı. Elektriksel ölçümler sonucunda numunenin yariiletken özellik sergilediği görüldü. Elektriksel iletkenlik eğrisi iki farklı iletkenlik bölgesi gösterdi ve numunede termal uyarımlı iletkenlik mekanizmasının baskın olduğu görüldü. InTe ince filminin optik özellikleri optik soğurma metoduyla araştırıldı. Numunenin optik band aralığ 1 ve lokalize enerji seviyelerinin genişliği soğurma spektrumunda belirlendi ve numunenin doğrudan band yapısına sahip olduğu görüldü. Yapılan optik ölçümler sonucunda, InTe ince filminin yasak enerji aralığı $1.38 \mathrm{eV}$ ve Urbach enerjisi de $0.27 \mathrm{eV}$ olarak bulundu. Numunenin optik sabitleri, geçirgenlik ve yansıma spektrumlarından hesaplandı ve optik sabitlerin dalgaboyuna ve frekansa bağlılığı araştırıldı. Numunenin kırılma indisi normal dispersiyon özelliği göstermekte ve kırılma indisi dispersiyonu tek osilatör modeline uymaktadır. Numunenin optik iletkenliği hesaplandı ve kompleks iletkenliğin reel ve sanal kısımlarının foton enerjisiyle arttığ 1 görüldü. InTe ince filminin fotoiletkenlik ölçümleri farklı 1 şı şiddetlerinde yapıldı. Akım-voltaj ve akım-zaman karakteristikleri numunenin fotoiletkenlik özelliğe sahip olduğunu gösterdi. İnce filmin alternatif akım iletkenliği (AC) farkl sıcaklıklarda frekansa bağlı olarak araştırıldı ve AC iletkenlik sonuçları numunede $\mathrm{CBH}$ (Correlated Barrier Hopping) iletkenlik mekanizmasının meydana geldiğini göstermektedir. Numunenin dielektrik sabitinin reel ve sanal kısımları frekans ve sıcaklıkla değişmektedir. Dielektrik sabiti sıcaklıkla artmaktadır. Çünkü sıcaklık arttığında elektrik

dipollerin yönelimi kolaylaşır ve bunun sonucunda dielektrik sabiti artar. Dielektrik sabitinin sanal kismının frekansa bağlılığı herhangi bir relaksasyon piki göstermedi. Böylelikle dielektrik relaksasyon (gevşeme) işlemini analiz etmek için elektrik modulus sonuçları kullanıldı. Elektrik modulusun reel kısmı frekansla artmakta ve yüksek frekanslarda sabit bir değere ulaşmakta, fakat düşük frekanslarda ise sıfıra yaklaşmaktadır. Elektrik modulusun sanal kısmının frekansa bağlılığı bir dielektrik relaksasyon piki göstermektedir. Bu pik sıcaklık artışıyla yüksek frekans bölgesine kaymakta yani numunede sicaklığa bağlı bir dielektrik relaksasyon meydana gelmektedir.Sonuçta hazırlanan InTe ince filmi amorf bir yariiletken malzemedir ve fiziksel özellikleri sıcaklıkla ve frekansla değişmektedir.

\section{TEŞEKKÜR}

$\mathrm{Bu}$ çalışma Fırat Üniversitesi Bilimsel Araştırma Projeleri Birimi tarafindan FUBAP-1170 nolu proje kapsamında desteklenmiştir. Yazarlar, maddi destek sağlayan Fırat Üniversitesi Bilimsel Araştırma Projeleri Birimi'ne teşekkür eder.

\section{KAYNAKÇA}

[1]E.Ü. Gündem, Electrical and Optical Propertıes of Amorphous Semiconductıng aSi:/A-SiN x : H Multilayer F1lms, Yüksek Lisans Tezi, Hacettepe Üniversitesi.

[2]J.D. Machenzie, "Electronic conduction in noncrystalline solids" J. Non-Cryst. Solids, vol. 2, pp 16-26, January 1970

[3]H.K. Rockstad, "Hopping conduction and optical properties of amorphous chalcogenide films" J. Non-Cryst. Solids, vol. 2, pp 192-202, January 1970.

[4]A. Masuda, Y.Yonezawa, A. Morımoto, M. Kumeda, and $\mathrm{T}$. Shimizu, Influence of $\mathrm{Pb}$ incorporation on light-induced phenomena in amorphous Ge100-x-yPbxSy thin films", J. NonCryst. Solids, vol. 7, no:2-3, pp 121-135, September 1997.

[5]J. Stuke, "Review of optical and electrical properties of amorphous semiconductors" J. Non-Cryst. Solids, vol. 4, pp 1-26, April 1970

[6]M. Pollak and T.H. Geballe, "Low-Frequency Conductivity Due to Hopping Processes in Silicon", Phys. Rev., vol. 122, pp 1742-1754, June 1961.

[7]I.G. Austın, , and N.F. Mott,"Polarons in crystalline and non-crystalline materials", Adv. Phys., vol. 18, no 71, p.41102, January 1969.

[8]G.E Pike,., "AC Conductivity of Scandium Oxide and a New Hopping Model for Conductivity”, Phys. Rev. B, vol. 6, pp 1572, August 1972.

[9]S.R. Elliott, "A theory of AC conduction in chalcogenide glasses”, Philos. Mag. B, vol.36, pp 1291-1304. July 1977.

[10]A.R Long., "Frequency-dependent loss in amorphous semiconductors", Adv. Phys., vol. 31, pp 553-637, June 1982.

[11]T. Mitsuyu, K. Wasa, "High Dielectric Constant Films of Amorphous LiNbO3 Prepared by Sputtering Deposition", JPn. J. Appl. Phys., vol. 20, no 1, pp L 48, December 1980 [12]N. Easwaran, C. Balasubramanian, , S.A.K. Narayandass, , D. Mangalaraj, "Dielectric and AC Conduction Properties of Thermally Evaporated Lithium Niobate Thin Films" Phys. Stat. Sol., vol. 129, pp 443, February 1992

[13]G. Shang, , K. Kunze, , M.J. Hampden, ," Lowtemperature chemical vapor deposition of indium sulfide thin films using a novel single-source indium thiocarboxylate compound as precursor", Smith. Chem. Vapor. Electron Depos., vol. 2, pp 242, November 1996

[14]C. Julien, , A. Chevy, , D. Siapkas, "Optical properties of In2Se3 phases", Phys stat Sol A, vol. 118, pp 553, April 1990.

[15]M. Yudasaka, T. Matasyoka, K.Nakanishi, "Indium selenide film formation by the double-source evaporation of indium and selenium", Thin Solid Films, vol. 146, pp 65, January 1987.

[16]A.I Zaslavskii., V.M. Sergeeva, "The Polymorphısm Of In2Te3”, Sov. Phys. Solid state, vol. 2, pp 2556, March 1961. [17]G.L . Bleris, T.Karakostas, N.A. Economov, R. De Ridder, "The ordered state of In $2 \mathrm{Te} 3$ and its relation to the transition state", Phys. Stat. Sol. A, vol. 50,pp 579, July 1978. 
[18]M.A.Afifi, E. Abd. El-Wahabb, A.E. Bekheet, H.E. Atyia, , "Effect of Annealing on the ac conductivity and the dielectric properties of In2Te3 thin films", Acta Phys. A, vol. 28, pp 403, September 2000.

[19]F.A. Jenkins, , H.E. White, Fundementals of Optics, McGraw-Hill, New York, 1957.

[20]M. Okutan, E. Basaran, H.I. Bakan, F. Yakuphanoglu, "AC conductivity and dielectric properties of Co-doped TiO2”, Physica B, vol. 364, pp 300-305, November 2005.

[21]F. Yakuphanoglu, M. Arslan, S.Z. Y1ldiz, "Determination and analysis of the dispersive optical constants of the 2,9,16,23 tetraneopentoxyphthalocyaninatozinc (II) charge transfer complex with 2,3-dichloro-5,6-dicyano- $\mathrm{p}$ - enzoquinone thin film". Volume 27, Issue 6, Pages 1153-1158, March 2005.

[22]N. F. Mott, , E.A. Davis, , Electronic Processes in NonCrystalline Materials: Clarendon Pres- Oxford, 595p, 1979.

[23]H. Oumous and H. Hadiri, "Optical and Electrical Properties of Annealed CdS Thin Films Obtained From a Chemical Solution", This Solid Films, vol. 386, pp 87-90, september 2001.

[24]J.I. Pankove, Optical Processes in Semiconductours, Prentice-Hall, Inc. Englewood cliffs, New Jersey, 1971.

[25]G.D. Cody, "A Comparison of the Optical Absorption edge of Crystalline and Amorphous Silicon, Semiconductors and Semimetals", (Academic Press, Orlando ), Vol.21B, p.11, December 1984.

[26]F. Yakuphanoglu, A. Cukurovali, İ. Yilmaz, "Refractive index and optical absorption properties of the complexes of a cyclobutane containing thiazolyl hydrazone ligand", Optical Materials, Vol. 27, pp 1363-1368, April 2005.

[27]D.A. Minkov, "Calculation of the Optical Constants of Thin Layer Upon a Transparent Substrate from the Reflection Spectrum”, J. Phys. D: Appl. Phys., vol. 22, pp 1157- 1161, May 1989.

[28]F. Yakuphanoglu, Y. Aydoğdu, U. Schatzschneider, E. Rentschler, "DC and AC conductivity and dielectric properties of the metal-radical compound: Aqua [bis(2dimethylaminomethyl-4-NIT-phenolato)]copper(II), Solid State Communications, vol 128, pp 63-67, october 2003

[29]H. Aydin, A. Tataroglu, A. Al-Ghamdi Ahmed, F. Yakuphanoglu, F. El-Tantawy, W.A Farooq, "A novel type heterojunction photodiodes formed junctions of $\mathrm{Au} / \mathrm{LiZnSnO}$ and $\mathrm{LiZnSnO} / \mathrm{p}-\mathrm{Si}$ in series", Journal of Alloys and Compounds, vol 625, pp 18-25, july 2015.

[30]M. Soylu, H. Aydin, A. A. Al-Ghamdi, W. A Farooq, F. Yakuphanoglu, "Study of optical and electrical assessments of the quaternary $\mathrm{MgZnSnO}$ system containing different $\mathrm{Mg}$ content", J Mater Sci: Mater Electron,, vol 25, pp 4235-4245, march 2014.

[31]C. Aydin, N.M. Khusayfan, A.A. Al-Ghamdi, F. ElTantawy, W.A. Farooq, F. Yakuphanoglu, "Facile synthesis, electrical and optical properties of $\mathrm{Cu}$-doped $\mathrm{GaN}$ nanorods by sol-gel technique", Journal of Sol-Gel Science and Technology, vol 78, pp 68-75, February 2016.

[32]H. Aydin, Sh.A. Mansour, C.Aydin, A. Al-Ghamdi, O.A. Al-Hartomy, F. El-Tantaw , F. Yakuphanoglu, "Optical properties of nanostructure boron doped $\mathrm{NiO}$ thin films", J Sol-Gel Sci Technol, vol 64, pp 728-733, may 2012. 